\section{Experience with growth hormone treatment in Great Britain}

The Medical Research Council working party which has been studying the clinical use of human growth hormone (hGH) in the treatment of children with short stature has recently published its final report. ${ }^{1}$ Patients treated in the trial included children with idiopathic hGH deficiency, some others with intracranial disorders with hGH deficiency, and a third group with a variety of miscellaneous conditions with and without hGH deficiency. Idiopathic deficiency of multiple pituitary hormones was much less common than idiopathic "isolated" hGH deficiency, whereas children with acquired pituitary disease, commonly due to a craniopharyngioma, usually had multiple hormone deficiencies.

When children were started on treatment early the longterm results were satisfactory: 77 patients have now reached their final adult height and 22 of the 47 with idiopathic hGH deficiency and 18 of the 30 with intracranial disease have achieved a height above the third centile for stature. Many of those who failed to reach the third centile were started on hGH at very late bone ages.

The prevalence of idiopathic hGH deficiency remains uncertain, since there is a considerable difference between the figures obtained by Parkin ${ }^{2} 3$ in Newcastle (about one in 30000 ) and in a more recent large study from Scotland 4 (about one in 5000). The reasons for this discrepancy are not clear, but it creates problems in predicting future requirements for hGH. The working party. estimated that an additional 136 new patients will need to be started on treatment in each of the next five years given that most patients with severe or partial hGH deficiency will be recognised and referred for treatment. Adequate supplies of hGH will need to be provided by the Department of Health and Social Security, with which responsibility for providing treatment now lies. ${ }^{5}$ The working party has taken a pessimistic view of the chances of enough hGH being made available and has suggested that all patients should be treated "until they are of a socially acceptable height." This is acceptance of second-best: surely all children should be given the treatment needed to bring them to their maximum height.

A second defect in the present system for treating these children is the delay in starting it. The mean age at the beginning of treatment in children with idiopathic "isolated" hGH deficiency remains unsatisfactorily high at $8 \cdot 1 \pm 0.6$ (SEM) years with a mean bone age of $5 \cdot 7 \pm 0.3$ years. The value of early treatment has been emphasised repeatedly, and the possibility of hGH deficiency should be in the mind of every clinician. With modern diagnostic facilities, treatment should be able to start before the age 5-6 years in most affected children.

All children who are very short (defined by a height that is 3.0 or more standard deviations below the mean for age), or who are less short but growing slowly, ${ }^{5}$ should be referred to an appropriate paediatrician, endocrinologist, or growth assessment centre (listed in the DHSS Health Circular $\mathrm{HC}(77) 21) .{ }^{6}$ Other diseases such as coeliac disease may then be excluded, and a positive clinical and laboratory diagnosis of hGH deficiency established by finding a low growth velocity, mild-to-moderate obesity, delayed bone age in the absence of hypothyroidism, and impaired hGH secretion during a valid dynamic test such as the insulin tolerance test.

How closely our management of growth hormone deficiency approaches the optimum should become apparent from the reports of the Health Service Human Growth Hormone Committee. This was recently set up to supervise the selection of patients for treatment, to determine treatment schedules, to maintain the overall supply of hGH, and to monitor the safety and effectiveness of treatment.

${ }^{1}$ Milner RDG, Russel-Fraser T, Brook CGD, et al. Experience with human growth hormone in Great Britain: the report of the MRS working party. Clin Endocrinol 1979;11:15-38.

${ }^{2}$ Lacey KA, Parkin JM. The normal short child. Community study of children in Newcastle upon Tyne. Arch Dis Child 1974;49:417-24.

${ }^{3}$ Parkin JM. Incidence of growth hormone deficiency. Arch Dis Child $1974 ; 49: 904-5$.

4 Vimpani GV, Vimpani AF, Lidgard GP, Cameron EHD, Farquhar JW. Prevalence of severe growth hormone deficiency. $\mathrm{Br}$ Med $\mathcal{F}$ 1977; ii $: 427-30$.

5 Parkin JM. Short stature. Br Med F 1976;i:1139-51.

6 Joint planning-health and local authorities: joint financing of personal social services projects. DHSS Health Circular HC(77)21, June 1977.

\section{A waste-cutting quango}

Cutting waste and getting better value for money are the current Government's philosophical aims, but setting up a quango to do it seems paradoxical. Nevertheless, the NHS Supply Council announced by $\mathrm{Mr}$ Jenkin last month ${ }^{1}$ may be justified by the wasteful way in which the NHS has used its massive purchasing power $-£ 1000$ million each year. Responsibility for buying supplies and equipment is divided among the DHSS supply branch (which arranges many contracts for the NHS) and various tiers of the Health Service. ${ }^{2}$ As successive reports have shown, ${ }^{3-7}$ too many of the purchases are made in an uncoordinated way, and the NHS does not get the best value for its money. The most recent assessment, that of the Salmon working group, ${ }^{7}$ criticised the division of responsibility and recommended a national supply council to draw up mandatory policies for health authorities.

After one and a half years' consultation the Secretary of State has established a policy-making council, with most of its members from the NHS. The council will have an independent chairman and include a representative of the health-care industry, the controller of supply at the DHSS, seven regional health authority nominees, and a doctor and a nurse nominated by the chief medical and nursing officers. The functions of the council, which will be funded by the health authorities, are vague and suggest that the tough animal envisaged by Salmon has had its teeth drawn: nowhere is enforcement mentioned.

Perhaps the council's lack of power reflects the Conservative philosophy of devolving power to the NHS or, just as likely, the DHSS's desire to protect its own interests and influence. The council "will advise ... on the organisation of supplies work" and "in consultation with authorities, users, and the supplies industry... develop policies and arrangements to enable authorities to make the best use of their supplies resources." In particular, it will arrange evaluation and information systems-work now done mainly by the DHSS. Since the council will have only a small secretariat it will have to rely on (and pay) th: DHSS and, where appropriate, health authorities to continue doing this -work. The danger is that unless the council's members are exceptionally well informed 
and expert it will not be strong enough to challenge and alter radically the deep-rooted habits that have made supplies purchasing so inefficient for the past 30 years.

${ }^{1}$ Department of Health and Social Security. Health services development: supply council. $\mathrm{HC}(80) 1$. London: DHSS, 1980.

${ }^{2}$ Anonymous. Medical and scientific equipment in the NHS. $\mathrm{Br} \mathrm{Med} \mathcal{F}$ 1978;ii:1160-1.

${ }^{3}$ Central Health Services Council. Report of the committee on internal administration of hospitals. London: HMSO, 1954. (Bradbeer Report.)

${ }^{4}$ Committee on Hospital Supplies. Final report. London: HMSO, 1958. (Messer Report.)

5 Committee on Hospital Supplies Organisation. Report. London: DHSS, 1966. (Hunt Report.)

6 Welsh Office. Buying for the National Health Service. HBSS 93/13/2. Cardiff: Welsh Office, 1976. (Collier Report.)

7 Supply Board Working Group. Report. London: DHSS. 1978.

\section{Exercise-induced asthma}

Asthmatic patients rarely blame exercise for bringing on their asthma, and most clinicians ask about other trigger factors first. For example, the highly reactive airways of asthmatic patients are known to respond vigorously to common allergens such as grass pollen and the house-dust mite as well as to such everyday activities as laughing. ${ }^{1}$ Inhaling substances such as histamine and acetylcholine may be used to detect over-reactive airways, and exercise has become used as a diagnostic test. ${ }^{2}$ If, then, exercise is a known cause for asthma, why are so few patients aware of the association? Partly the answer must be that the asthma usually follows exercise rather than arises during muscular exertion-about four or five minutes' continuous exercise is needed to precipitate wheeze and dyspnoea. ${ }^{3}$ Few patients exercise that long and in those who do the asthma appears after exercise has ceased so that they may not link the two events.

Even if exercise-induced asthma is rarely important clinically, it has provoked intense research interest, largely concentrated on the potential stimuli for its onset. ${ }^{4}$ The latest and most convincing theory has been posed by McFadden and Ingram, ${ }^{5}$ who postulate that cooling of the airway is the primary stimulus. The onset of physical exertion produces an increase in minute ventilation to provide sufficient oxygen for the metabolic needs of working muscles. Herxheimer ${ }^{6}$ first incriminated hyperventilation as the prime stimulus, and McFadden and Ingram have now shown that this results in large volumes of incompletely conditioned air being repeatedly inspired, drying and cooling the upper airways as heat and water are transferred from their surface. The total quantity of heat exchanged varies directly with minute ventilation and inversely with the temperature and water content of the inspired air. This attractive concept of respiratory heat loss as the initiating event unifies many divergent views, but it does not explain how heat loss generates airways obstruction. A vagal reflex seems likely, but this does not exclude the possibility that histamine or other mediators are released. ${ }^{4} 7$

The practical aspects of exercise-induced asthma are straightforward. The condition is seen largely in children, ${ }^{8}$ probably because they exercise more than adults, and usually responds rapidly to inhaled bronchodilators. Often the attacks can be prevented by prior treatment with bronchodilators ${ }^{39}$ or sodium cromoglycate. ${ }^{10}$ If an asthmatic patient has occasional asthmatic episodes treated with inhaled bronchodilators, the simplest and best recommendation is that bronchodilator should be inhaled before sustained exercise, instead of adding a new treatment. ${ }^{9}$ If this advice does not suffice and attacks are important-if, for example, the patient is actively engaged in sport-then cromoglycate inhalations can be used prophylactically. More rarely, the occurrence of exercise-induced asthma may indicate inadequate control, though other features such as nocturnal attacks are usually more prominent. In such cases regular additional treatment may be required, such as inhaled steroids. The part played by steroids in preventing exercise-induced asthma itself is uncertain. Treatment with atropine may not always be successful and large doses may be required.

The type of exercise may have some bearing on the generation of asthma: swimming has been thought least likely to produce it. ${ }^{11}$ This observation can be explained on the heat flux theory ${ }^{12}$ : the air being inhaled by a swimmer is usually well saturated with water and is warmer than the ambient air inhaled during running out of doors. Children may therefore be warned to expect that exercise-induced asthma is more likely when playing games requiring sustained running outside but less likely if they swim or engage only in sprint activities.

1 Gayrard P. Should asthmatic patients laugh ? Lancet 1978;ii:1105-6.

2 Godfrey S. Exercise induced asthma. In: Clark TJH, Godfrey S, eds. Asthma. London: Saunders Chapman and Hall, 1977:56-78.

3 Anderson SD, Silverman M, König P, Godfrey S. Exercise-induced asthma. $B r \mathcal{F}$ Dis Chest 1975;69:1-39.

4 Hartley JPR. Exercise-induced asthma. Thorax 1979;34:571-4.

$5 \mathrm{McFadden}$ ER, Ingram RH. Exercise-induced asthma. Observations on the initiating stimulus. $N$ Engl $F$ Med 1979;301:763-9.

${ }^{6}$ Herxheimer H. Hyperventilation asthma. Lancet 1946;i :83-7.

${ }^{7}$ Ferris L, Anderson SD, Temple DM. Histamine release in exerciseinduced asthma. $\mathrm{Br}$ Med 7 1978;i:1697.

8 Jones RS, Buston MH, Wharton MT. The effect of exercise on ventilatory function in the child with asthma. $\mathrm{Br} \mathcal{F}$ Dis Chest $1962 ; 45: 78-86$.

${ }^{9}$ Hetzel MR, Batten JC, Clark TJH. Do sympathomimetic amines prevent exercise-induced asthma by bronchodilatation alone? $\mathrm{Br} \mathcal{F}$ Dis Chest $1977 ; 71: 109-14$

${ }^{10}$ Davies SE. Effect of disodium cromoglycate on exercise-induced asthma. Br Med F 1968;iii:593-4.

11 Fitch KD, Morton AR. Specificity of exercise in exercise-induced asthma. Br Med $\mathcal{F} 1971$;iv:577-81.

12 Deal EC, McFadden ER, Ingram RH, Jaeger JJ. Hyperpnea and heat flux: initial reaction sequence in exercise-induced asthma. $\mathcal{F} A p p l$ Physiol $1979 ; 46: 476-83$.

\section{Schizophrenia in different cultures}

In 1973 the World Health Organisation published the results of a remarkable investigation, its International Pilot Study of Schizophrenia, ${ }^{1}$ in which research workers from nine countries collaborated to study 1200 patients. They used a special psychiatric interview (the Present State Examination) to elicit symptoms in a standard way which led to a uniform and reliable clinical diagnosis-as well as the possibility of diagnosis by a computer program called CATEGO. ${ }^{2}$ The investigators established that patients with an identical pattern of symptoms could be recognised in Colombia, Czechoslovakia, Denmark, India, Nigeria, Taiwan, the USSR, Britain, and the United States. The finding of a closely similar clinical picture in such diverse places supports the view that schizophrenia is a disease or a group of diseases and not merely a label applied to social deviants, as some writers have suggested.

Now the WHO group has published ${ }^{3}$ the results of a logical extension of this first investigation: a two-year follow- 